\title{
Analysis on the Ecological Pattern Succession of Vegetations in Xiliaohe Plain under the Water Change Condition
}

\author{
Zhang Qiuxia ${ }^{1,2, a}$, Chen Minjian ${ }^{1, b}$, Wang Fang ${ }^{1, c}$, Chu Limin ${ }^{1, c}$ \\ ${ }^{1}$ China Institute of Water Resources and Hydropower Research, Beijing, China \\ ${ }^{2}$ PowerChina Resources Ltd., Beijing, China \\ azqx815@163.com, bmjchen@iwhr.com, cwangf@iwhr.com, d11906433@qq.com
}

Key Words: water condition, vegetation composition, vegetation succession, Xiliaohe Plain

Abstract: The change of water condition directly influences the composition and succession of regional vegetation communities. In this study, the Xiliaohe Plain was selected to systematically analyze the succession of vegetation's ecological pattern under the change of water condition in semi-arid area. Based on zonality theory and runoff formation principle and combined with field investigation of vegetation, the main community composition of zonality, non zonality and transitional vegetation in Xiliaohe Plain was analyzed in this study. It was concluded that: under the condition of sufficient recharge from rainfall and groundwater, the vegetation communities mainly include meadow vegetation communities and shrub \& subshrub communities; when the groundwater depth is decreased to the level which is unable to recharge water for vegetation, there will be succession of the original zonal community; when there is abundant recharge from rainfall and underground water, the vegetation communities mainly include the hankow willow, artemisia halodendron, etc; when the succession was finished and became stable, the zonal vegetation represented by Leymus chinensis community and stipa grandis community was formed.

\section{Introduction}

Study on the response and change law of ecosystem under the influence of human disturbance is an important part of eco hydrological research. The increase of water resources development and utilization in semi-arid area has seriously changed the water conditions of the ecosystem, and directly led to the succession and degradation of surface vegetation in semi-arid region. Previous studies have analyzed the typical vegetation changes in the regional and watershed scales under the change of water conditions [1-3]. With the increase of regional human activities and the intensity of water resources development and utilization, a series of succession of vegetation ecology in semi-arid area occurred correspondingly. Study on the change of vegetation's ecological pattern driven by regional water condition is of great significance for ecological conservation and restoration in semi-arid region.

The succession process and pattern of vegetation in Xiliaohe Plain was analyzed in this study by regarding the change of water conditions as the driving factor of succession and combining with the analysis and field investigation on the change of regional water conditions and vegetation composition. It provides support for the study on the rational development and utilization and ecological protection of regional water resources. 


\section{Vegetation Investigation and Composition Analysis}

The vegetation in semi-arid region of China is located in the temperate grassland area which is an important part of Eurasian grassland area, and it is continuously distributed in Songliao Plain, Inner Mongolia plain, loess plateau, etc with a very wide area [4]. Xiliaohe plain is the main part of Khorchin sandy land, and it is located in the east of Xiliaohe basin and west of Songliao Plain, with an area about $52,000 \mathrm{~km} 2$. The natural vegetation in the region is mainly characterized by sparse forest and grassland, and the main vegetation is semi arid shrub and semi shrub grassland [5].

\section{Vegetation Investigation}

This study was made by taking comprehensive consideration into the soil texture, spatial layout, water condition and other factors, and 14 investigation points were selected from Xiliaohe Plain to conduct the investigation on the vegetation and underground depth. The investigation contents include the community type, community coverage, species composition, species richness, root depth, etc, with details shown in the table 1.

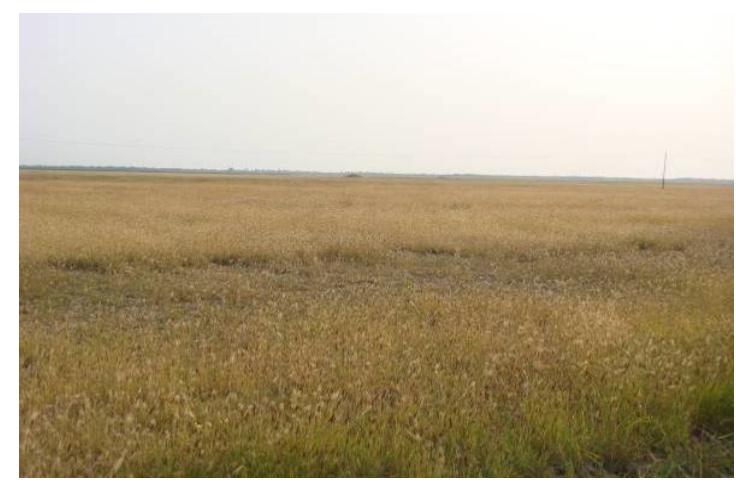

Fig.1 Chloris Virgata Community in Horqin Left Middle Banner

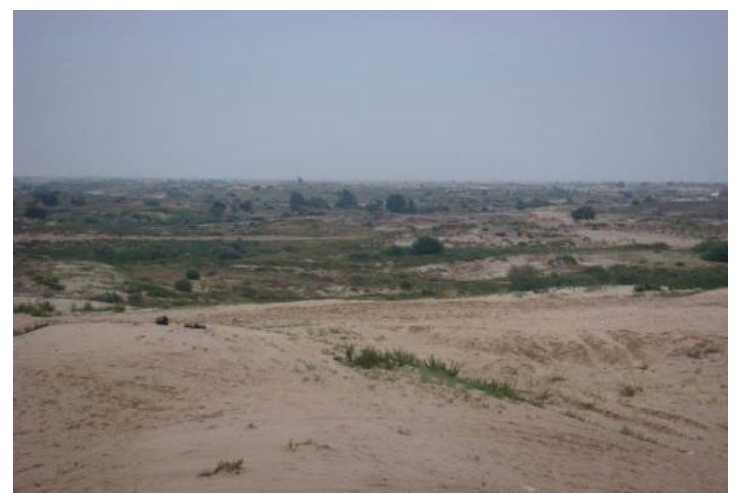

Fig.3 Desert Shrub Ground in Naiman Banner

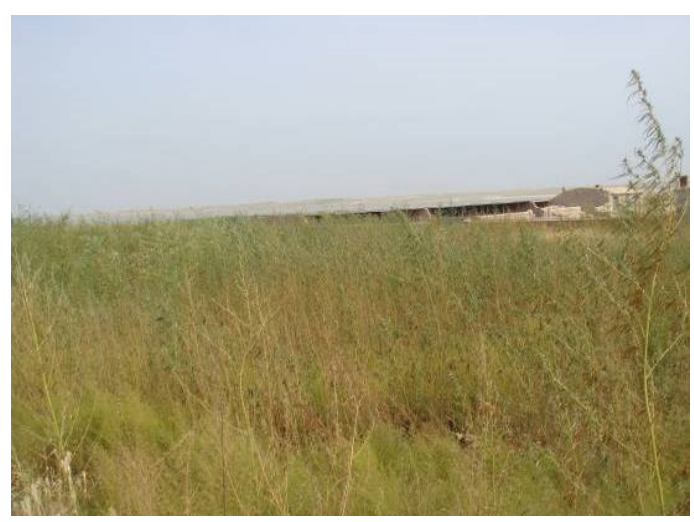

\section{Fig.2 Successional Pioneer Species -} Artemisia Scoparia in Jarud Banner

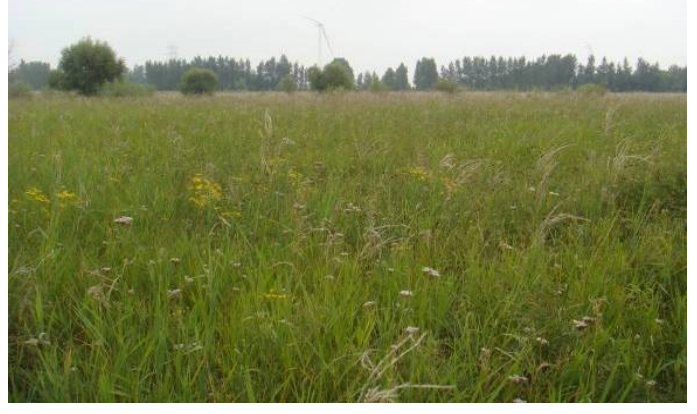

Fig.4 Enclosed Meadow in Horqin Left Back Banner 
Table 1 Investigation and Statistics of Vegetation in the Xiliaohe Plain

\begin{tabular}{|c|c|c|c|c|}
\hline Type & $\begin{array}{c}\text { Number of sample } \\
\text { points }\end{array}$ & Geographical location & Community type & $\begin{array}{c}\text { Community } \\
\text { coverage }\end{array}$ \\
\hline \multirow{13}{*}{$\begin{array}{c}\text { Natural } \\
\text { vegetation }\end{array}$} & \multirow{11}{*}{13} & Horqin Left Back Banner & $\begin{array}{l}\text { Pennisetum - salsola collina - green bristlegrass } \\
\text { community }\end{array}$ & Medium \\
\hline & & Naiman Banner & $\begin{array}{l}\text { Chloris virgata + green bristlegrass- artemisia } \\
\text { scoparia-Eragrostis pilosa community }\end{array}$ & Medium \\
\hline & & Naiman Banner & $\begin{array}{l}\text { Chloris virgata+ artemisia scoparia-Stipa } \\
\text { glareosa commuity }\end{array}$ & Medium \\
\hline & & Naiman Banner & $\begin{array}{l}\text { Echinops gmelini -Artemisia scoparia } \\
\text { community }\end{array}$ & Medium \\
\hline & & Naiman Banner & $\begin{array}{l}\text { Elm sparse woods (three layers of } \\
\text { arbor-shrub-grass compounds) }\end{array}$ & Medium \\
\hline & & Horqin Left Back Banner & $\begin{array}{l}\text { Artemisia scoparia+ green bristlegrass- } \\
\text { Atraphaxis manshurica- Caragana stenophylla } \\
\text { community, with distribution of sparse willow }\end{array}$ & Medium \\
\hline & & Jarud Banner & Artemisia scoparia community & High \\
\hline & & Jarud Banner & Stipa grandis+Lespedeza davurica community & High \\
\hline & & $\begin{array}{l}\text { Horqin Left Middle } \\
\text { Banner } \\
\end{array}$ & Chloris virgata community & Medium \\
\hline & & $\begin{array}{c}\text { Horqin Right Middle } \\
\text { Banner }\end{array}$ & Chloris virgata & Medium \\
\hline & & $\begin{array}{l}\text { Horqin Right Middle } \\
\text { Banner }\end{array}$ & Chloris virgata-salsola collina community & Low \\
\hline & & Horqin Left Back Banner & $\begin{array}{c}\text { Sedge - hispid arthraxon- Asiatic plantain } \\
\text { community }\end{array}$ & High \\
\hline & & Horqin Left Back Banner & $\begin{array}{l}\text { Reed + Calamagrostis brachytricha and } \\
\text { broad-leaved herb community }\end{array}$ & High \\
\hline $\begin{array}{l}\text { Artificial } \\
\text { vegetaton }\end{array}$ & 1 & $\begin{array}{l}\text { Horqin Left Middle } \\
\text { Banner }\end{array}$ & Corn & High \\
\hline
\end{tabular}

\section{Vegetation Composition}

This paper mainly focuses on the relationship between vegetation community and regional hydrological conditions. According to the mechanism of hydrological ecological effect, based on the zonal theory and runoff formation principle and combined with the existing study and investigation results, the Xiliaohe plain vegetation is divided into 3 major categories: zonal vegetation, non-zonal vegetation and transitional vegetation from zonal nature to non-zonal nature.

Zonal vegetation can fully reflect the climate characteristics of an area. Zonal vegetation sustains its growth by relying on the non-runoff part of rainfall, including the water for plant transpiration and soil evaporation in order to maintain the plant growth environment. This part of water is not influenced by the development and utilization of water resources [6]. The zonal vegetation in Xiliaohe plain is mainly distributed in the zonal chestnut soil area and belongs to the typical grassland vegetation community, including steppe community, stipa grandis community, sand-grass community, thick cleistogenes chinensis community, wheatgrass community, echinops gmelini community, etc.

Non-zonal vegetation, also known as intrazonal vegetation, refers to a type of vegetation which grows and develops under the influence of non-zonal factors including the underground water, 
surface water, geomorphologic position or components of the earth surface, etc in a certain climate zone or macroclimate zone, such as the meadow vegetation, swamp vegetation, aquatic vegetation, etc; the growth of non-zonal vegetation needs the water recharge from both local rainfall and runoff, and this part of water recharge is influenced by the development and utilization of water resources. The non-zonal vegetation in Xiliaohe plain includes the meadow vegetation, shrub and subshrub vegetation relying on the underground water recharge, arbor and artificial vegetation. The non-zonal arbor vegetation includes elm steppe-woodland community, wild apricot community and Chinese pine + mongolian oak community as well as the artificial poplar forest, Pinus sylvestri forest, etc. The non-zonal shrub and subshrub steppe vegetation includes the caragana microphylla community, atraphaxis manshurica, lespedeza daurica schindl community and artemisia frigida community. The non-zonal meadow vegetation mainly includes the sedge community, phragmites australis community and Chinese pennisetum community.

The transitional vegetation from zonal nature to non-zonal nature includes the succession pioneer plant community and vegetation community in initial stage of succession. The transitional vegetation from zonal nature to non-zonal nature in Xiliaohe plain includes the arbor community, shrub and subshrub community and typical steppe community. The transitional vegetation from zonal nature to non-zonal nature in arbor community mainly includes the hankow willow community. The transitional type shrud and subshrub vegetation from non-zonal nature to zonal nature mainly includes the periploca shrub community and artemisia halodendron semi-shrub community. The transitional vegetation from non-zonal nature to zonal nature in the typical steppe vegetation mainly includes the chloris virgata community and artemisia scoparia community.

\section{Vegetation Succession Analysis}

\section{Influencing Factors}

The influencing factors of vegetation succession can be broadly divided into two categories: internal cause and external cause. The influencing factors of vegetation succession can also be divided into biotic and abiotic factors. In the Xiliaohe plain, the main factors influencing vegetation succession are the human reclamation, overgrazing and water resources development \& utilization.

Through analysis on the succession of sandy grassland vegetation in Naiman county, Zhao Tingning et al believed that the rapid degradation of sandy grassland is the result of the combined stress of climate change and human activities [7]; unreasonable production method of animal husbandry is the main factor leading to the ecosystem deterioration of sandy grassland in this area, and the climate change aggravates the deterioration degree of system. Wang Tao et al also classified the influencing factors of the desertification process of the Khorchin sandy land into 2 categories: human activity and climate change; human activity is the main influencing factor, including over grazing, excessive chopping and collecting and aldn reclamation, especially the change of land utilization type which leads to the catastrophic damage of natural vegetation community [8].

\section{Succession Pattern}

Vegetation succession direction includes progressive succession and retrogressive succession. Vegetation in Xiliaohe plain is a main part in Khorchin sandy land, and there are many related studies on the succession of this vegetation. It can be analyzed according to succession process and succession direction. 
(1) Stage characteristics of succession

According to the stage characteristics of vegetation succession, the vegetation succession in Xiliaohe plain can be divided into 3 stages: pioneer plant, mid-term plant and later-stage plant.

(2) Restoration succession of vegetation

Analysis can be made fron different perspectives according to the vegetation succession directions, and some researchers summarize the overall vegetation succession mode in Khorchin sandy land as follows: agriophyllum squarrosum community - atemisia halodendron community and salix gordejevi community - wheatgrass steppe or cleistogenes squarrosa teppe or leymus chinensis steppe - shrub invasion steppe - elm woodland-steppe. The restoration successtion mode of degraded vegetation in sand area is summarized as follows: annual plant community dominated by the pioneer plant - agriophyllum squarrosum (moving dune stage) - shrubartemisia halodendron and the community dominated by annual and biennial herbs (semi-mobile and semi-fixed dune stage) - weed community dominated by the annual and biennial herb and perennial herb (fixed dune stage) [9-10].

(3) Degraded succession of vegetation

Zuo Xiaoan et al provided the vegetation composition and its important value of the grazing forest - sandy steppe - fixed dune - semifixed dune during the grassland degeneration [11].

\section{Analysis on the Vegetation Succession in Xiliaohe Plain under the Water Change Condition}

In combination with the vegetation investigation data and existing study on the vegetation succession, the vegetation succession process and pattern in Xiliaohe plain was analyzed by regarding the changes of water conditions are the driving factor of succession. See the Fig.5. With the changes of water conditions, especially the change in the recharge effect of underground water to the vegetation, the succession of vegetation community shows a succession process of non-zonal meadow - non-zonal arbor and shrub \& subshrub vegetation - zonal typical steppe vegetation.

Under sufficient water condition, when the groundwater depth is shallow, rainfall and groundwater is the source for vegetation to absorb water, and the main vegetation type is the non-zonal meadow vegetation; when groundwater is not sufficient to maintain the wet environment, but can supply the roots uptake water for arbor and shrub \& subshrub vegetation, the main vegetation type is non-zonal arbor and shrub \& subshrub vegetation; when groundwater depth is large and surface vegetation only rely on rainfall recharge, the main vegetation type is the typical grassland vegetation. 


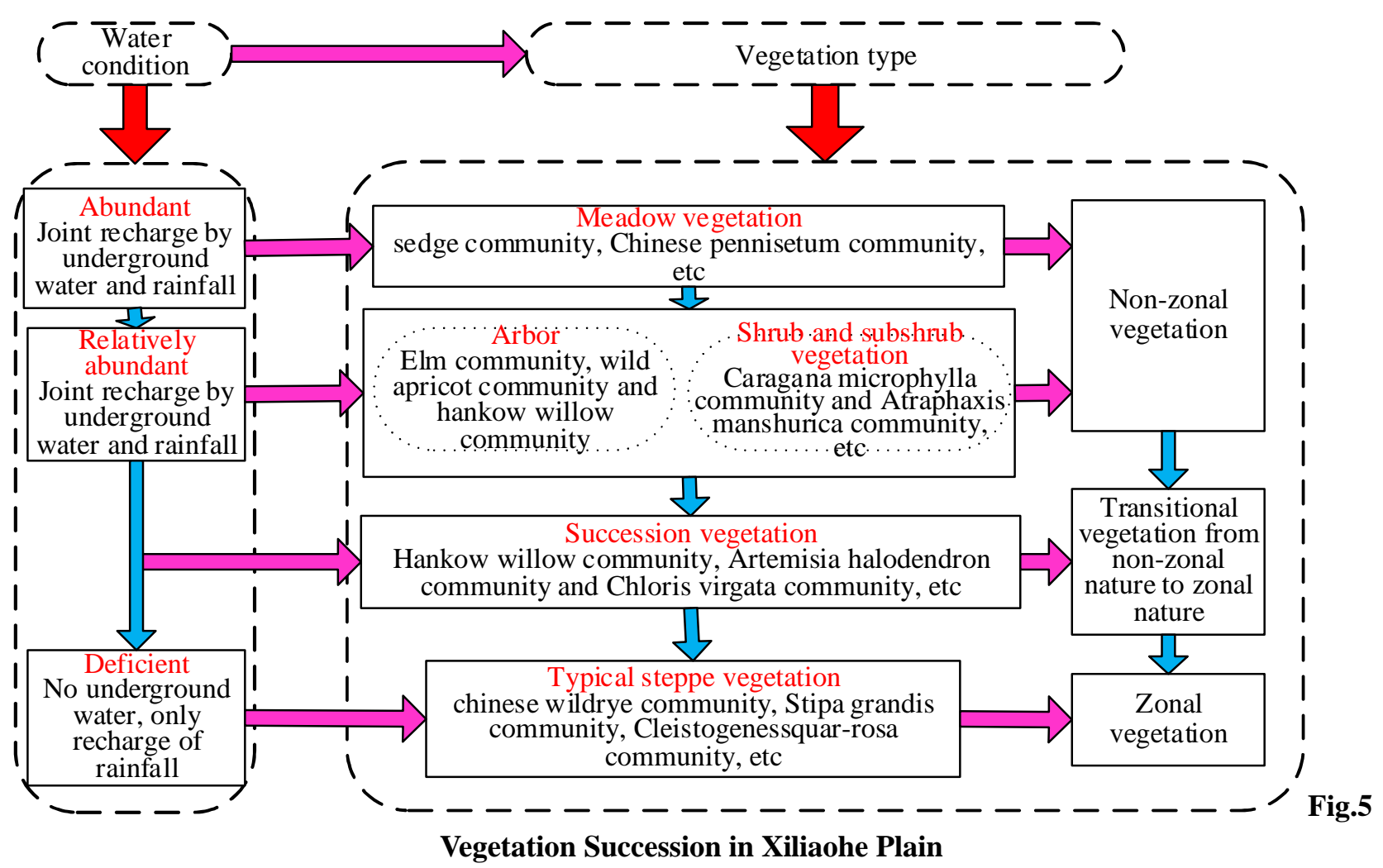

\section{Conclusion}

This study selects the Xiliaohe plain as the typical representative area in the semi arid region, and then analyzes the main zonal, non-zonal and transitional succession vegetation composition in the Xiliaohe plain according to the zonal theory by virtue of the vegetation investigation and analysis. In combination with the runoff formation principle, this study analyzes the succession process of regional vegetation under the change of water conditions, and discusses the succession process of typical community of regional vegetation under the different water recharge conditions of rainfall and underground water. This study provides basic theoretical support for ecological protection of regional vegetation and water resources development \& utilization.

\section{Acknowledgements}

This work was financially supported by the Youth Fund of National Natural Science Foundation of China (No.51409271).

\section{Reference}

[1] P. M. Saco1, G. R. Willgoose1, G. R. Hancock. Eco-geomorphology of banded vegetation patterns in arid and semi-arid regions [J]. Hydrology and Earth System Sciences. 2007, 11: 1717-1730.

[2] Andrew J Elmore, Sara J Manning, John F Mustard, Joseph M Craine. Decline in alkali meadow vegetation cover in California: the effects of groundwater extraction and drought [J]. Journal of Applied Ecology 2006. 43(4): 770-779.

[3] P.S. Lake. Perturbation, restoration and seeking ecological sustainability in Australian flowing waters [J]. Hydrobiologia. 2005, 552: 109-120. 
[4] Hou Xueu, Sun Shizhou and Zhang Jingwei et al. Vegetation Map of the People's Republic of China, hina Cartographic Publishing House, 1979.

[5] Cao Jun, Wu Shaohong and Yang Qinye. Land Use and Desertification in Horqin Sandy Land [J]. Journal of Desert Research. 2004, 24 (5): 548-552.

[6] Wang Fang, Liang Ruiju, Yang Xiaoliu, Chen Minjian. A study of ecological water requirements in northwest China I: theoretical analysis [J]. Journal of Natural Resources. 2002, 17(1): 1-8.

[7] Zhao Tingning, Cao Zilong, Zheng Cuiling and Sun Baoping. Primary Study on Sandy Grassland Degradation of Horqin in Case of Naiman County [J]. Science of Soil and Water Conservation. 2003, 1(4): 45-49.

[8] Wang Tao, Wu Wei, Zhao Haling, Hu Mengchun and Zhao Aiguo. Analyses on Driving Factors to Sandy Desertification Process in Horqin Region [J]. Journal of Desert Research. 2004, 24(5): 519-528.

[9] Li Shengong, Zhao Aifen and Chang Xueli. Several Problems of Vegetation Succession in Horqin Sandy Land[J]. Journal of Desert Research. 1997, 17(supplementary issue 1): 25-33.

[10] Zuo Xiaoan, Zhao Haling, Zhao Xueyong, Guo Yirui, Zhang Tonghui, Mao Wei, Su Na and Feng Jing. Species Diversity of Degraded Vegetation at Different Restoration Years in Horqin Sandy Land[J]. Acta Prataculturae Sinica. 2009, 18(4): 9-16.

[11] Zuo Xiaoan, Zhao Xueyong, Zhao Halin, Guo Yirui, Li Yuqiang and Zhao Yuping. Characteristics of Species Composition and Functional Diversity in Grassland Degradation in Horqin Sandy Land[J]. Journal of Soil and Water Conservation. 2006, 20(1): 181-185. 